\title{
Hazard and risk based allocation of safety instructions to operators handling pesticides
}

\author{
Beate Lichtenberg ${ }^{1} \cdot$ Uwe Mischke $^{1} \cdot$ Sandra Scherf $^{2} \cdot$ Markus Röver $^{2}$. \\ Sabine Martin ${ }^{1}$
}

Published online: 21 August 2015

(c) The Author(s) 2015. This article is published with open access at Springerlink.com

\begin{abstract}
Prior to authorisation of plant protection products (PPP) according to Regulation (EC) No $1107 / 2009$ it must be ensured that products placed on the market will not impair the health of humans and animals if used appropriately and as intended.

For safe use of pesticides, it is generally necessary to assign obligatory instructions for operators to comply with risk mitigation measures.

These instructions are allocated due to the intrinsic toxicological properties of the products combined with qualitative exposure aspects, e.g. for different formulation types and application scenarios. The toxicological properties of PPP are evaluated on the basis of the uniform principles according to Regulation (EC) No 1107/2009, and are communicated by the classification and labelling of the products. Additionally, quantitative exposure estimations carried out within the risk assessment for the products might result in additional instructions for safe use. Those instructions aim to ensure, that the respective toxicological reference value will not be exceeded. The latter issue will be addressed in another article.

The general principles for assigning mandatory instructions for professional and non-professional operators of PPP concerning human health are based
\end{abstract}

Beate Lichtenberg

beate.lichtenberg@bfr.bund.de

1 Federal Institute for Risk Assessment (BfR), Berlin, Germany

2 Federal Office of Consumer Protection and Food Safety (BVL), Braunschweig, Germany on the classification and labelling of PPP according to Regulation (EC) No 1272/2008 (CLP-Regulation). Plant protection products are classified based on toxicological tests (mainly acute toxicity, irritation and sensitisation) and on conventional methods based on the above mentioned Regulation (mainly for subacute and chronic effects).

Since the CLP-Regulation is obligatory for classification and labelling of mixtures such as PPP from 1 June 2015 onwards, it will be necessary to replace BBA uniform principles for safeguarding the health of applicators of plant protection products (1993) Part 1, 3-3 and adapt its principles for assigning PPE and instructions for safe use on the basis of the new classification and labelling principles for products. This article will provide the necessary support for risk management decisions concerning human health. It presents principles to implement, adapt and specify the rather imprecise provisions concerning the use of PPE laid down in CLP-Regulation to the particular requirements for handling and applying PPP.

It might be a basis for European harmonisation concerning allocation of risk mitigation measures to professional and non-professional operators of pesticides, thus, adjusting the different levels of operator protection in the Member States, as stated in Regulation (EC) No 1107/2009.

Keywords Hazard and risk assessment · Human health - Pesticides - Personal protective equipment . Classification and labelling of products . Professional and non-professional operators . Home and allotment garden · Agriculture 
Zusammenfassung Vor der Zulassung eines Pflanzenschutzmittels muss gemäß Verordnung (EG) Nr. 1107/2009 sichergestellt werden, dass in Verkehr gebrachte Produkte bei sachgerechtem und bestimmungsgemäßem Gebrauch die Gesundheit von Mensch und Tier nicht beeinträchtigen.

Für den sicheren Umgang mit Pflanzenschutzmitteln ist es generell notwendig, dem Anwender verbindliche Anweisungen zum Einhalten von Risikominderungsmaßnahmen zu erteilen.

Persönliche Schutzausrüstung wird zum einen aus den intrinsischen toxikologischen Eigenschaften der Mittel, kombiniert mit qualitativen Expositionsaspekten für verschiedene Formulierungstypen und Applikationsszenarien abgeleitet. Diese ergeben sich aus der Bewertung nach den einheitlichen Grundsätzen gemäß Verordnung (EG) Nr. 1107/2009 und werden durch die Einstufung und Kennzeichnung der Mittel kommuniziert. Ergänzend können sich weitere Auflagen aus der quantitativen Expositionsabschätzung im Rahmen der Risikobewertung der Produkte ergeben. Diese Auflagen sollen sicherstellen, dass der entsprechende toxikologische Referenzwert nicht überschritten wird. Der letztgenannte Themenbereich wird in einem weiteren Artikel dargestellt.

Die generellen Prinzipien zur Vergabe von obligatorischen Anweisungen für professionelle und nicht-professionelle Anwender von Pflanzenschutzmitteln hinsichtlich der menschlichen Gesundheit basieren auf der Einstufung und Kennzeichnung gemäß der Verordnung (EG) Nr. 1272/2008 (CLP-Verordnung). Pflanzenschutzmittel werden gestützt auf toxikologische Tests (hauptsächlich akute Toxizität, Reizung und Sensibilisierung) und nach den konventionellen Methoden entsprechend der CLPVerordnung (vorwiegend subakute und chronische Effekte) eingestuft.

Da die CLP-Verordnung für die Einstufung und Kennzeichnung von Gemischen, wie z. B. Pflanzenschutzmitteln, ab dem 1. Juni 2015 verbindlich anzuwenden ist, ist es notwendig, die BBA Richtlinie für die Prüfung von Pflanzenschutzmitteln im Zulassungsverfahren, Kennzeichnung von Pflanzenschutzmitteln - Gesundheitsschutz (1993) Part 1, 3-3 zu ersetzen und die in ihr dargelegten Prinzipien zur Zuordnung von PSA und Auflagen für die sichere Anwendung auf Basis der neuen Prinzipien zur Einstufung und Kennzeichnung von Produkten anzupassen. Dieser Artikel unterstützt die notwendigen Risikomanagement-Entscheidungen hinsichtlich der menschlichen Gesundheit. Er stellt die maßgeblichen Prinzipien zur Umsetzung, Anpassung und
Konkretisierung der eher unpräzisen Vorgaben zum Gebrauch von PSA gemäß Verordnung (EG) Nr. 1272/2008 an die besonderen Erfordernisse bei der Handhabung und Ausbringung von Pflanzenschutzmitteln vor.

Dieser Artikel kann daher eine Basis für die EU-weite Harmonisierung hinsichtlich der Vorgabe von Risikominderungsmaßnahmen für professionelle und nicht-professionelle Anwender von Pflanzenschutzmitteln sein und dadurch die unterschiedlichen Anwenderschutzniveaus in den Mitgliedstaaten angleichen, wie in der Verordnung (EG) Nr. 1107/2009 ausgeführt.

\section{Introduction}

Plant protection products shall only be placed on the market if they do not have adverse effects on human health according to Regulation (EC) No 1107/2009. The precautionary principle should be applied. According to Directive 2009/128/EC on sustainable use of plant protection products the Member States shall adopt the necessary measures to ensure that the handling of these products does not pose an unacceptable risk to human health. Up to now, there are different levels of protection in the Member States (Regulation (EC) No 1107/2009). Therefore, harmonised principles are necessary for the approval of active substances, authorisation and mutual recognition of PPP in the Member States of the European Union (EU). The data requirements for PPP are given in Commission Regulation (EU) No 284/2013. This Regulation also sets out test methods and specifies information to be submitted including classification and labelling and necessary risk mitigation measures.

Regulation (EC) No 1272/2008 on classification, labelling and packaging of substances and mixtures ensures that hazards are clearly communicated to users in the EU through classification and labelling. The method of classification and labelling is based on the United Nations globally harmonised system (GHS).

In order to meet the requirements for human health, it can be necessary for authorisation to assign particular protective measures for people handling or applying pesticides directly (professional or nonprofessional 'operators'), for people during subsequent work in treated crops ('workers' or nonprofessional gardeners during re-entry tasks in the home and allotment garden) and/or for uninvolved people such as 'bystanders' (people unintentionally present during or shortly after application of a plant 
protection product) and 'residents' (people living in the vicinity of the area where PPP are or have been applied). This article deals with operators exclusively.

The necessity of protection measures arises from the intrinsic toxicological potential of hazardous products as usually indicated by its classification and labelling and from exposure estimations which may reveal that a reference value will be exceeded. In this article the principles underlying allocation of risk mitigation measures, namely PPE based on the classification and labelling of PPP, and/or other specific measures, e.g. in the case of applications in the home and allotment garden area (as tactile warnings or child-resistant fastenings) are presented exclusively. How to assign risk mitigation measures based on comparison of estimated exposure with relevant reference values will be addressed separately in another article.

Associated with individual hazard (H)-statements, particular codes of precautionary (P)-statements for prevention, response, storage, disposal and general behaviour are given by the CLP-Regulation. However, there are only very few P-statements, e. g. 'Wear protective gloves/protective clothing/eye protection/face protection'. (P280) or '[In case of inadequate ventilation] wear respiratory protection.' (P284) referring to personal protective equipment. Therefore, this article presents the principles to adapt and specify the rather imprecise provisions concerning the use of PPE laid down in the CLP-Regulation to the particular requirements for handling and applying PPP.

\section{Classification and labelling of plant protection products}

Plant protection products are classified based on toxicological tests (mainly acute toxicity, irritation and sensitisation) as well as on conventional methods based on the above mentioned CLP-Regulation (mainly for subacute and chronic effects). In the latter case, available toxicity data for all components should be provided as part of an application in order to assess cumulative effects of active substances with non-active substances like safeners, synergists and other relevant co-formulants.

Apart from legal classification and labelling the main sources of information are the safety data sheets according to Article 31 of Regulation (EC) No 1907/2006 (REACH-Regulation, cf. data requirements for PPP according to Regulation (EU) No 284/2013). Based on data requirements of the REACH-
Regulation, toxicological information is mainly limited to acute toxicity, i.e. often no information on other endpoints is available. In addition, the industry is responsible for classification of co-formulants. This sometimes leads to different classification and labelling of substances with identical CAS No by different manufacturers and distributors. Both, these data gaps and the diversity in classification and labelling of coformulants might result in a strong inequality of classification and labelling of PPP. This, in turn, entails different levels of protection in Member States.

A first step forward towards harmonised classification of PPP could be the use of information for the REACH registration of substances submitted to the European Chemicals Agency (ECHA). Thus, the following sources of information should be considered for the evaluation of co-formulants: harmonised classification and labelling for substances, results from other authorisation procedures (e.g. active substance in PPP, biocidal products etc.), opinions of the Committee for Risk Assessment (RAC opinions) on proposals for harmonised classification and labelling, Chemical Safety Reports (if available) or registration submission dossiers (ECHA Dissemination Website) (resp. IUCLIDs could be used as well, if available), Material Safety Data Sheets and other information, if available.

\section{General provisions}

In general, operators have to comply with Good Agricultural Practice (BMELV 2010). In addition, irrespective of particular hazardous properties of PPP leading to their labelling, the following general instructions are basically necessary for PPP in order to comply with occupational hygienic requirements for appropriate handling of biologically active products. They are considered as minimum mandatory instructions. Further PPE might be used e.g. by allergic subjects or other susceptible people.

First, according to Regulation (EC) No 1272/2008, it is considered a pre-requisite for health protection that instructions for use are read and carried out, both by professional as well as by non-professional operators. Thus, the phrase:

- 'To avoid risks to human health and the environment, comply with the instructions for use.' (EUH401).

must be included in the label. 
Furthermore, the phrases

- 'Avoid any unnecessary contact with the product. Misuse can lead to health damage.',

- 'Do not eat, drink or smoke when using this product.'

and

- 'Wear work clothing during handling and applying plant protection products.' (for professional operators)

or

- 'Wear long-sleeved shirt and long trousers during handling and applying plant protection products.' (for non-professional operators)

have to be assigned.

Since operators handling PPP may be potentially exposed to various products, the phrase

- 'If medical advice is needed, have product container or label at hand.'

will be mandatory in Germany if no correspondent P101 statement is assigned to the product. According to Regulation (EC) No 1272/2008, allocation of this statement is generally only highly recommended for the general public.

In cases where no correspondent P102 statement needs to be allocated to PPP according to Regulation (EC) No 1272/2008 (generally highly recommended only for the general public as for P101), the phrase

- 'Keep out of children's reach.'

is mandatory for instructions for use as well.

Some active substances of PPP possess particular toxicological properties that are not covered by the toxicological endpoints taken into account by the CLPRegulation and are therefore not classified or labelled. However, these properties may be relevant for operators handling these products. Hence, special instructions for use need to be assigned to such products.

Artificially produced pyrethroids, for instance, and products containing active substances of this group, are known to cause burning of the skin without classical signs of irritation on the skin surface. Therefore, operators have to be informed about this phenomenon and skin contact should be avoided. This is done using the following instructional text:

- 'If the plant protection product comes into contact with skin (especially facial), it can cause burning or itching, without external signs of irritation. These effects must be regarded as a warning to avoid further exposure at all costs. If the symptoms do not disappear, or if they are joined by further symptoms, a doctor must be consulted.'

There are no concentration limits of pyrethroids for this allocation.

As a further example, thiram, an active substance used predominantly as a fungicide in PPP, shows effects similar to the disulfiram containing pharmaceutical 'Antabus'. It dramatically enhances effects of alcohol consumption, since metabolism of alcohol is reduced by enzyme inhibition. Thus, the phrase

- 'No alcohol must be consumed before, during or after working with the plant protection product.'

is to be allocated, e.g. to thiram-containing PPP.

Some PPP contain micro-organisms as the active ingredient, which may be allergenic. Since there are no adequate tests for clearly proving sensitising potential of micro-organisms available, this must be indicated as follows:

- 'The packaging must be provided with the wording "Micro-organisms may have the potential to provoke sensitising reactions.".'

\section{Professional operators}

If PPP need to be classified and labelled regarding human health according to the CLP-Regulation, appropriate PPE has to be worn in order to protect operators from potential health risks. Table 1 depicts the principles of assigning risk mitigation measures, i.e. PPE to professional operators handling and applying PPP depending on product labelling with various $\mathrm{H}$-statements.

Normally, only PPE but no other mitigation measures are allocated due to classification and labelling for professional operators. All PPE mentioned in this table for professional operators need to comply with the requirements for PPE laid down in the 'Guidelines for requirements concerning personal protective equipment in plant protection' (BVL 2006) (including up-dated versions in the future). To underline this, the phrase:

- 'The directive concerning requirements for personal protective equipment in plant protection, "Personal protective equipment for handling plant protection products" of the Federal Office of Consumer Protection and Food Safety must be observed'.

has to be included in instructions for use. 


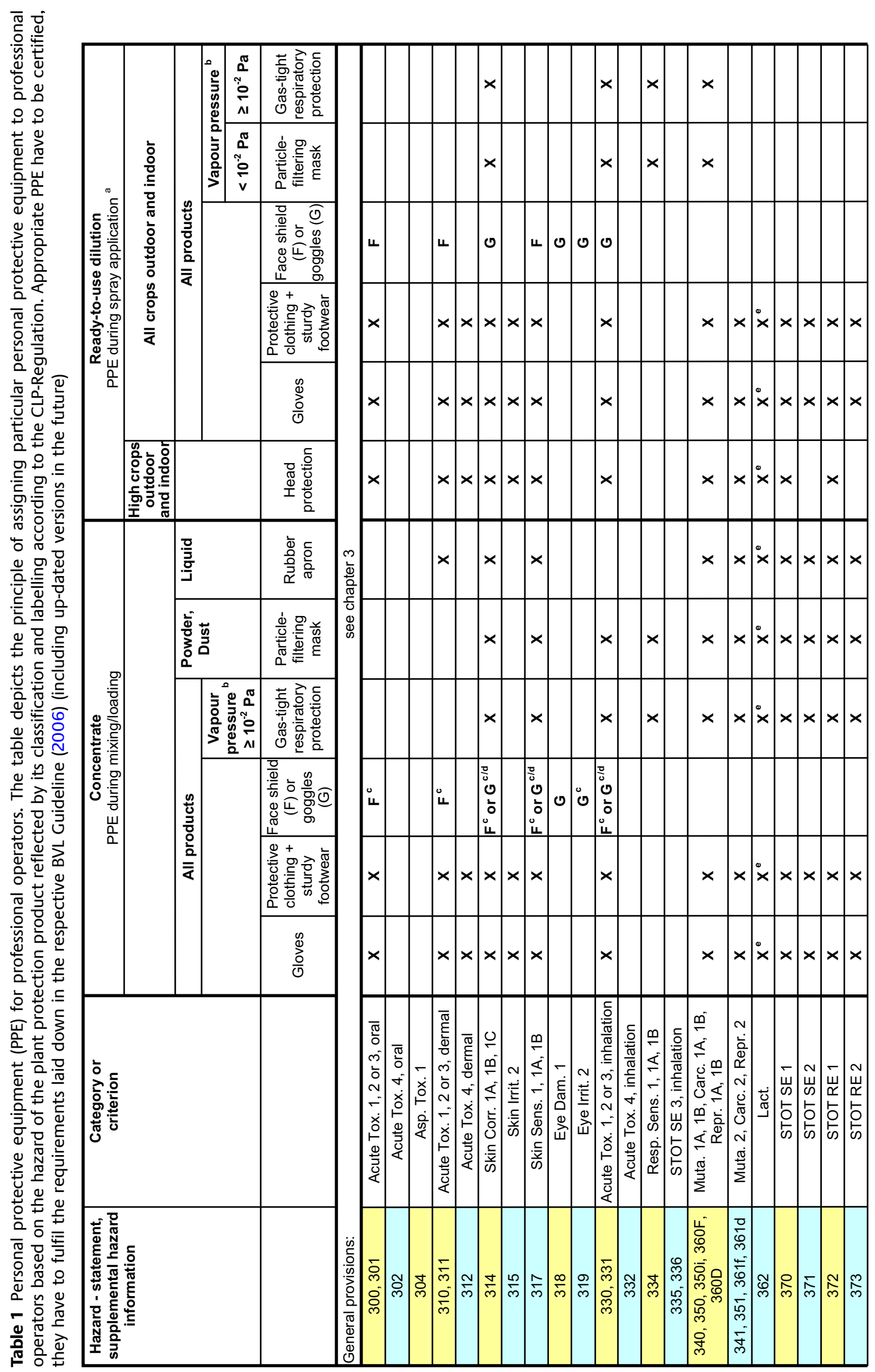



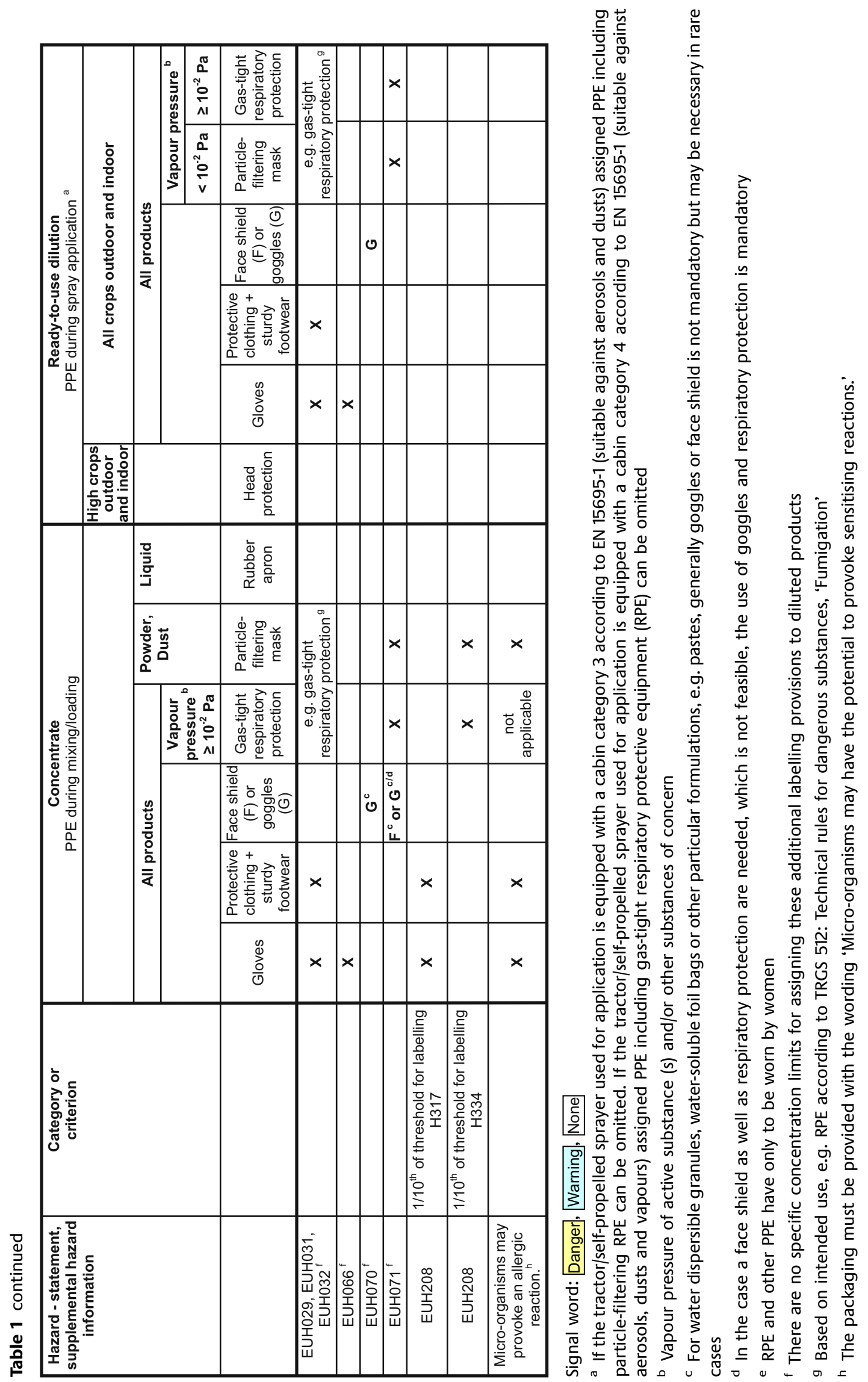


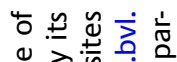

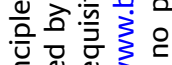

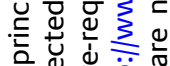

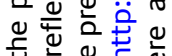

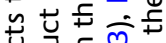

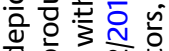

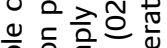

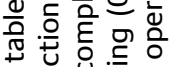

幽 웡

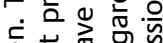

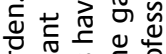

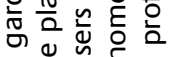

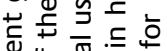

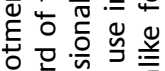

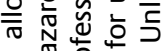

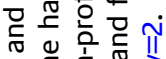

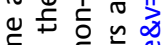

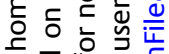

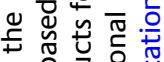

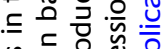

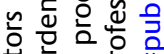

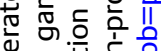

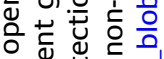

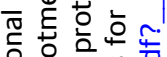

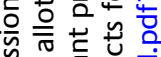

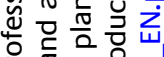

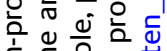

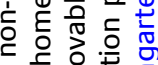

으음

品

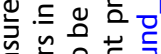

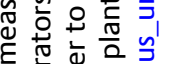

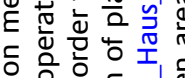

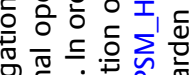

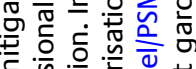

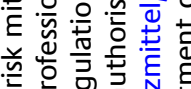

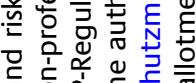

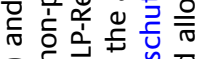

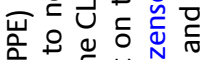

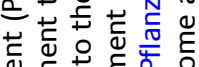

ه 토원

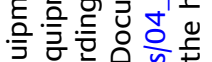

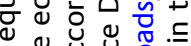

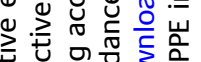

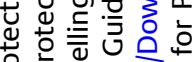

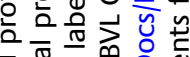

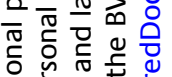

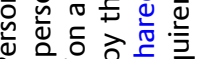

g苞可

N.

ำำ

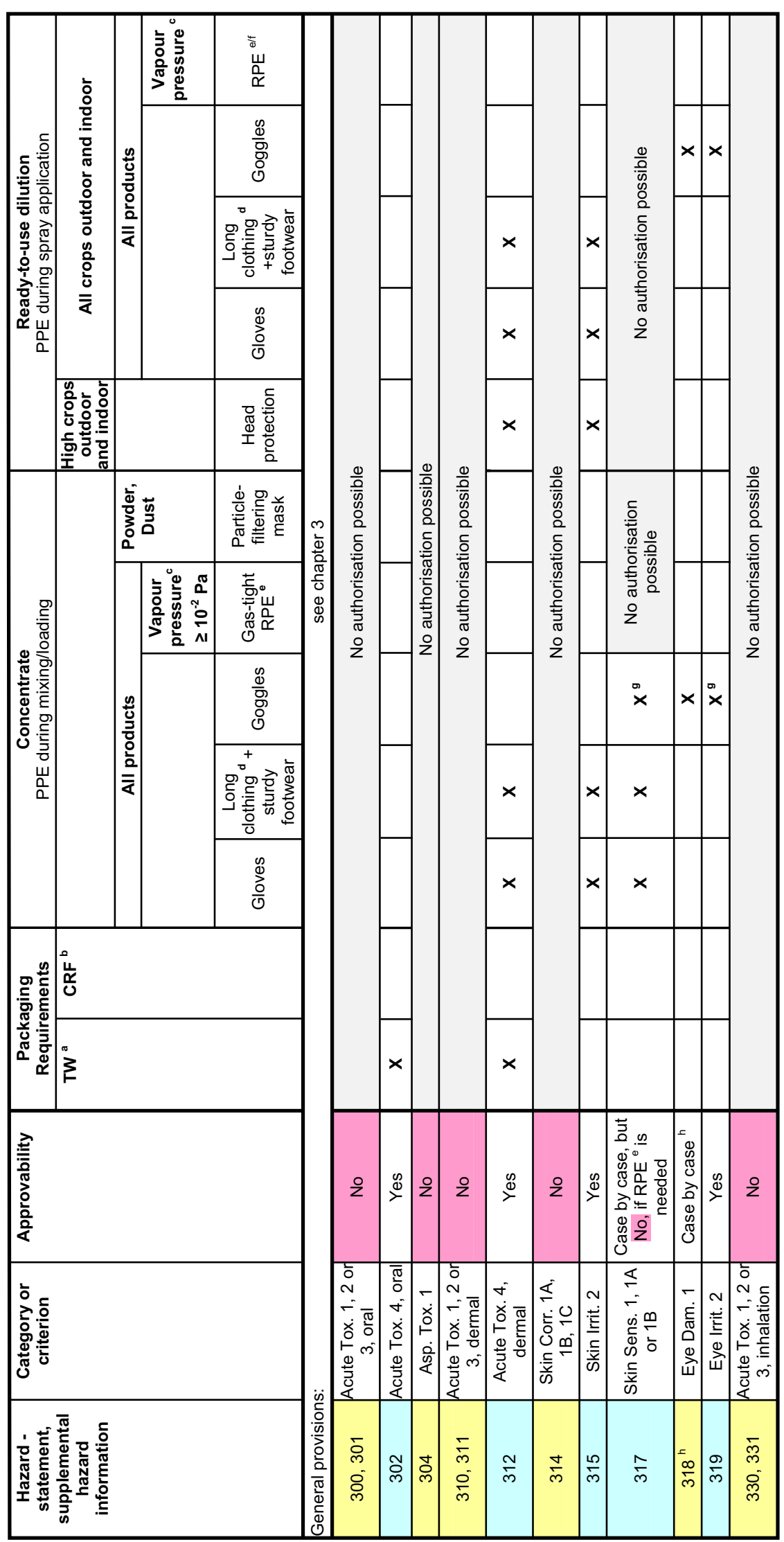




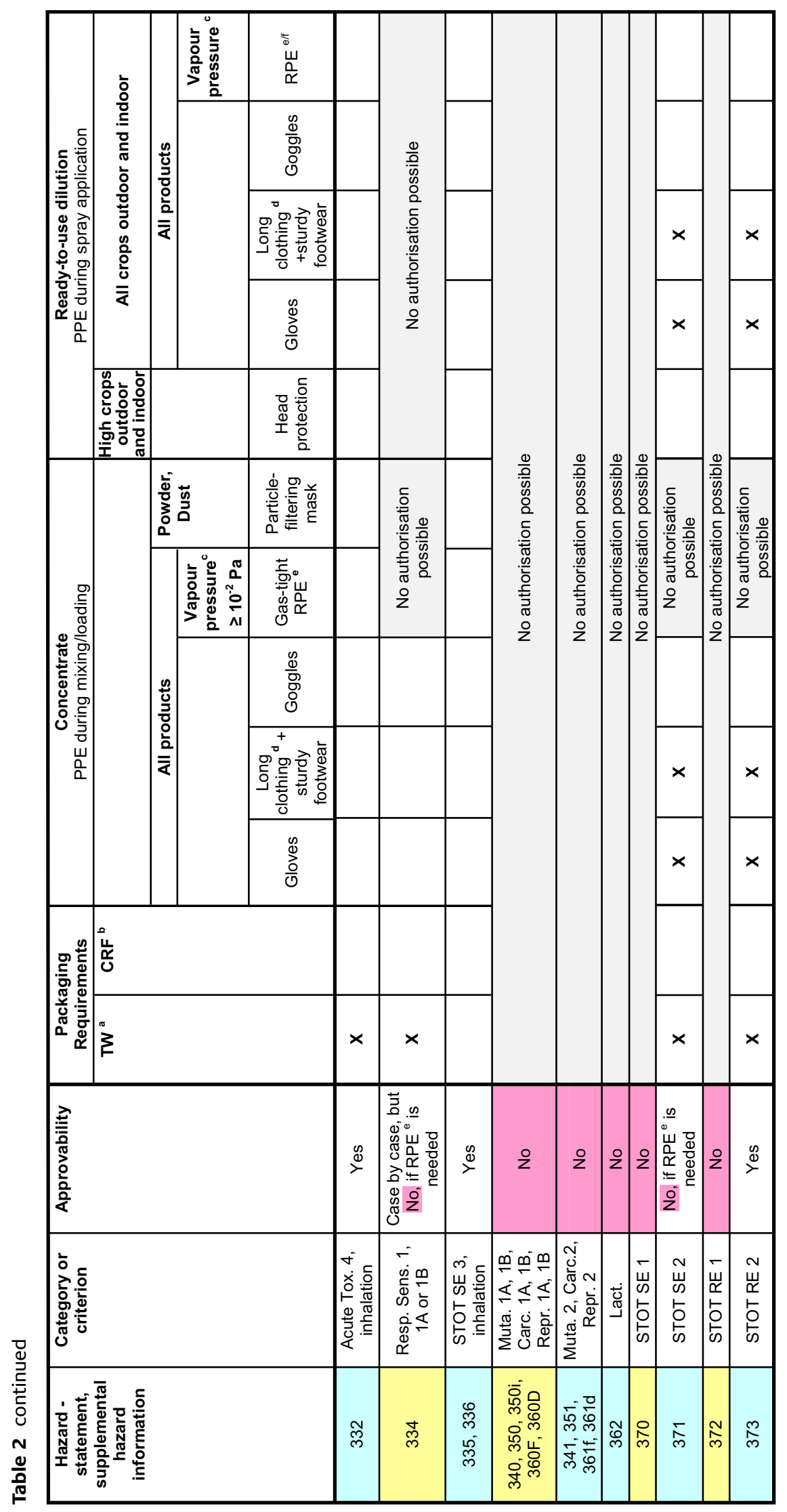




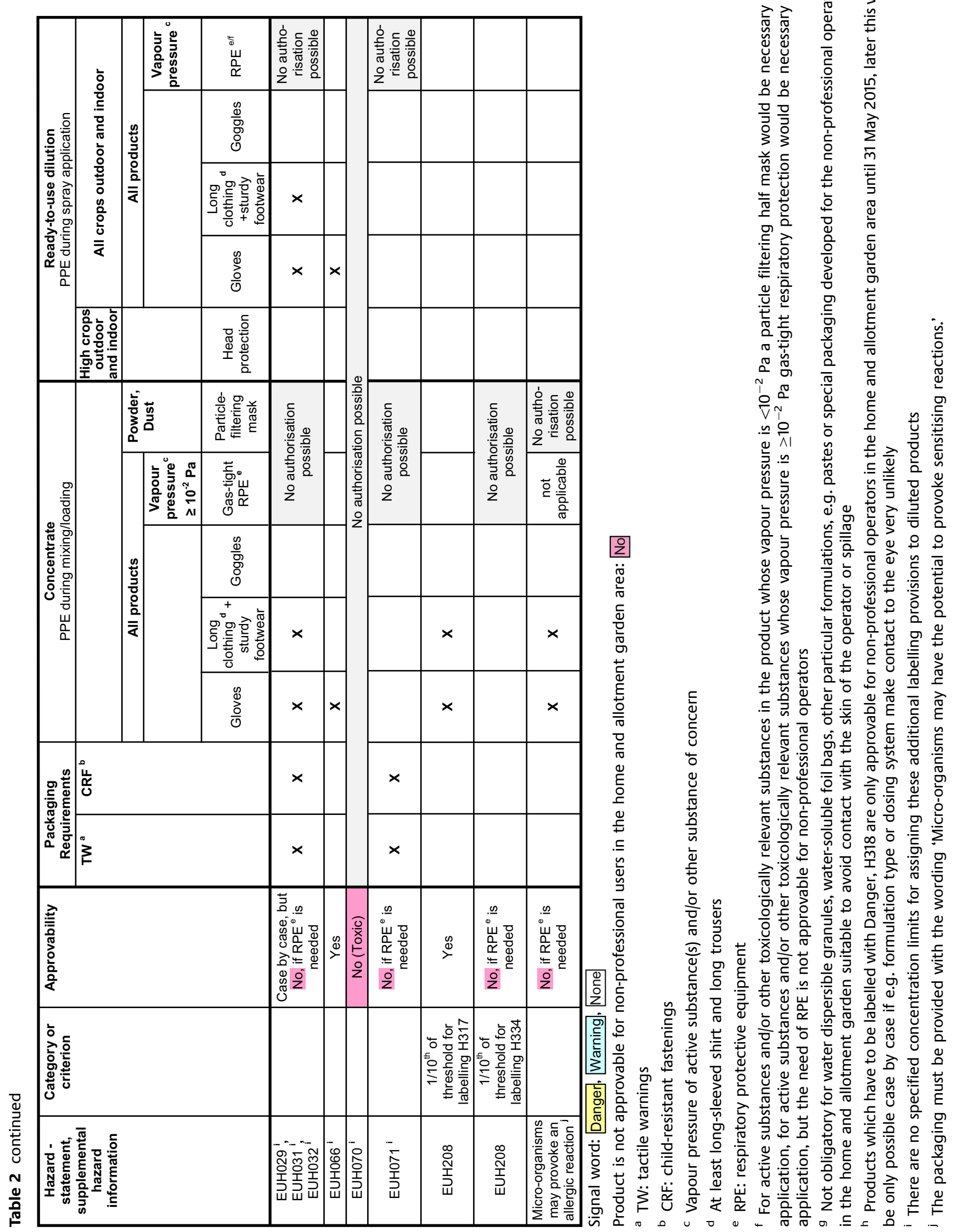


Columns 3-8 of Table 1 refer to the undiluted, concentrated product, i.e. mixing/loading tasks are affected. The PPE given in columns 9-14 of the table has to be used during application of the ready-to-use dilution if this dilution fulfils the requirements for being labelled with the respective H-statement (cf. column 1 of the table). In this article it is assumed that the PPP will be applied by spraying. For all other application techniques, e. g. spreading of granules or fumigations, allocation of PPE for application should be appropriately modified on a case-by-case basis. If there are particular other national regulations, e.g. TRGS 900 (Occupational exposure limits) and TRGS 512 (Fumigations), these have to be taken into account.

In the case of the concentrate, it is important for assigning appropriate PPE to consider how the product is formulated. For instance, in case of a powder formulation inhalable dust might occur. In the case of the H-statement 334, 'May cause allergy or asthma symptoms or breathing difficulties if inhaled', respiratory protection is deemed necessary. The type depends on the vapour pressure of the active substance and/or additional toxicological relevant ingredients of the product. If the product contains relevant volatile substances, i.e. with vapour pressures $\geq 10^{-2}$ Pa (EFSA Guidance 2014), gas-tight respiratory protection is needed. For respective substances in powder/dust formulations with vapour pressures $<10^{-2} \mathrm{~Pa}$, certified particle filtering masks are necessary.

On the other hand, if a plant protection product is a liquid formulation, inhalable droplets during mixing/loading are less relevant and respiratory protection shall thus only be considered for products containing relevant volatile substances, i.e. with vapour pressures $\geq 10^{-2} \mathrm{~Pa}$. Nevertheless, the concentrated liquid can be spilled on clothes or skin, so that a rubber apron is necessary for products labelled with e.g. H314 ('Causes severe skin burns and eye damage'), in addition to certified protective clothing, gloves and face shield (or goggles + respiratory protection, as explained below for powdery products labelled with H331 and other cases in Table 1) during mixing/loading.

For allocating appropriate PPE during application (see columns 9-14 of the table), various application scenarios are taken into account, i.e. indoor and outdoor applications to high or low crops. Spraying high crops will probably result in airborne spray mist at overhead level, so that head protection might need to be worn, in addition to certified protective clothing and gloves (based on H312, 'Harmful in contact with skin', for example).
It should be noted that during the last years technical progress has been made in tractor and selfpropelled sprayer design in order to better protect operators applying PPP so that tractors and self-propelled sprayers typically are fitted with closed, certified cabins now. This development is very much appreciated and is supported by allocating modified instructions for use if these tractors are used.

Hence, provided that tractors equipped with certified, closed cabins are used in combination with tractor-mounted, trailed or self-propelled application equipment, the otherwise assigned PPE could be omitted as long as the operator stays in the closed cabin. If the operator has to leave the cabin, e.g. in order to check or repair the application equipment, wearing of the allocated PPE is required. In order to re-enter the cabin, the PPE has to be taken off beforehand and stored within a box located outside the cabin.

Therefore, the following phrase is proposed for the instructions for use:

- 'When applying the product with tractor-mounted, trailed or self-propelled application equipment, only vehicles with closed pressurized cabins (e.g. cabin category 3 , if no respiratory protective equipment or particle-filtering masks are necessary or category 4 , if gas-tight respiratory protective equipment is needed acc. to EN 15695-1 and -2) are suited to replace personal protective equipment during application. During all other activities outside of the cabin the prescribed personal protective equipment must be worn. In order to avoid contamination of the cabin, it is not permitted to enter the cabin with contaminated personal protective equipment (it should be deposited e.g. in an appropriate storage facility). Contaminated gloves should be washed before removing the gloves and hands should be washed before entering the cabin with pure water, respectively.'

In cases where a face shield and respiratory protection should be worn simultaneously according to Table 1-either during mixing/loading and/or during spraying-(which is not feasible), the use of goggles instead of a face shield is considered mandatory additionally to the appropriate respiratory protection and in addition to all other assigned PPE, e.g. for powdery products labelled with H331 ('Toxic if inhaled').

The examples given above refer to PPP with single hazard-statements. For those which need to be labelled with more than one H-statement, all 
necessary PPE are summed up and included into instructions for use.

\section{Non-professional operators in the home and allotment garden area}

In order to comply with the legal requirements of Regulation (EC) No 1107/2009 and the German Plant Protection Act (02/2012), the German Competent Authority [Federal Office of Consumer Protection and Food Safety (BVL)] published criteria to decide whether or not a plant protection product is suitable for the use in the home and allotment garden area and therefore can be authorised for non-professional operators. The criteria underlying this decision, either hazard-based or on the basis of other considerations, e.g. packaging size and type, dosing system and type of PPE necessary for use have been set out in the BVL Guidance Document on 'The authorisation of plant protection products for non-professional users and for use in home gardening' (02/2013). Thus, PPP that are acutely toxic, category 1,2 or 3 , corrosive, category $1 \mathrm{~A}, 1 \mathrm{~B}$ or $1 \mathrm{C}$ or reprotoxic, carcinogenic or mutagenic category $1 \mathrm{~A}, 1 \mathrm{~B}$ or 2 or PPP that need to be handled or applied wearing respiratory protective equipment (for details it is referred to the Guidance Document, $2.2 \mathrm{a}-\mathrm{c}$ ), basically cannot be authorised for the use in the home and allotment garden area. Moreover, it is stated in this Guidance Document that products classified as sensitising can only be approved if the ready-to-use dilution is not considered sensitising any more, i.e. if it contains less than $1 \% \mathrm{w} / \mathrm{w}$ (or less than the specific concentration limit) of relevant sensitising components.

In principle, the criteria for allocating PPE to nonprofessional operators due to the classification and labelling of the PPP are the same as for professional users of PPP. But, in contrast, the term PPE refers to e.g. gloves and goggles that can be freely purchased by non-professional operators in construction markets or drugstores.

Table 2 gives an overview of the PPE assignment for non-professional operators in the home and allotment garden area based on classification and labelling of the product. The table structure is substantially the same as for Table 1.

For ease of comparison with the table on professional users of PPP, those PPP with classifications and labelling falling under the cut-off criteria specified by the BVL Guidance Document on PPP in the home and allotment garden area are included in the table, even though these criteria would lead to non-approval (see red and grey highlighting).

All conditions causing the need of respiratory protective equipment during mixing/loading or application of a PPP according to Table 2 will lead to rejection of authorisation for the use in the home and allotment garden area (see above). If a PPP labelled with 'Warning', H317 ('May cause an allergic skin reaction') is formulated as a powder, a particlefiltering half-mask would be mandatory during mixing/loading. Thus, this product cannot be approved for non-professional operators.

Products labelled with H304 ('May be fatal if swallowed and enters airways'), with H318 ('Causes severe eye damage') or with H334 ('May cause allergy or asthma symptoms or breathing difficulties if inhaled') are linked to the signal word 'Danger' according to the CLP-Regulation, which normally leads to rejection of approval for non-professional operators, since these products cannot be authorised as low-risk products from 1 June 2015 onwards. However, products labelled with H318 or H334 could be exceptionally authorised for non-professional use on a case-by-case basis if particular risk mitigation measures, e.g. special packaging, dosing systems or other technical measures, make skin or eye contact with the undiluted product unlikely. For products labelled with H304 no particular risk mitigation measures can be prescribed to lower the potential exposure, so that these products cannot be approved for the use in the home and allotment garden area.

Unlike for professional users of PPP, additional provisions for packaging might be allocated for nonprofessional users in the home and allotment garden area due to classification and labelling of PPP (cf. 4th and 5th column in Table 2). These can be tactile warnings (TW) for visually impaired people and/or child-resistant fastenings (CRF), for example.

\section{Conclusion}

A pre-requisite for safe use of pesticides bearing intrinsic toxicological hazards is to assign harmonised obligatory instructions for operators to wear PPE or to comply with other risk mitigation measures, such as specific requirements for the packaging. The described principles of assigning personal protective equipment to professional and non-professional operators handling and applying PPP are based on the classification and labelling of the products. 
The intrinsic toxicological properties of the products are evaluated on the basis of the uniform principles according to Regulation (EC) No 1107/2009. Classification and labelling of PPP must be carried out according to the CLP-Regulation, which is obligatory for mixtures from 1 June 2015 onwards.

Plant protection products are classified based on the required toxicological tests as well as on conventional methods based on the CLP-Regulation. Especially for medium and long-term toxicological endpoints of the products, no studies are required. Hence, available toxicity data for all components should be provided in order to assess cumulative effects of active substances together with relevant coformulants. Therefore, information for the REACH registration of substances submitted to the European Chemicals Agency (ECHA) should be used.

Harmonised obligatory instructions for operators to wear personal protective equipment (PPE) and harmonised other risk mitigation measures contribute to a safe use of PPP and to more transparency and comprehensibility. Additionally, exposure evaluation carried out within the risk assessment for the products might result in additional instructions and further risk mitigation measures for operators in order to ensure, that the respective toxicological reference values will not be exceeded.

It is intended to apply the principles presented in this article for the authorisation of plant protection products on a national level.

This paper might contribute to the EU-wide harmonisation process concerning allocation of PPE and other risk mitigation measures within the authorisation. Since types and technical details of PPE still differ between the Member States further effort is necessary in order to establish uniform provisions.

Open Access This article is distributed under the terms of the Creative Commons Attribution 4.0 International License (http://creativecommons.org/licenses/by/4.0/), which permits unrestricted use, distribution, and reproduction in any medium, provided you give appropriate credit to the original author(s) and the source, provide a link to the Creative Commons license, and indicate if changes were made.

\section{References}

BBA Uniform Principles for Safeguarding the Health of Applicators of Plant Protection Products (Uniform Principles for Operator Protection) (1993) Part I, 3-3, 'Richtlinien für die Prüfung von Pflanzenschutzmitteln im Zulassungsverfahren, Kennzeichnung von Pflanzenschutzmitteln, Gesundheitsschutz'
BMELV (2010) Brochure 'Gute fachliche Praxis im Pflanzenschutz’ (Good Agricultural Practice), http://www.bmel.de/ SharedDocs/Downloads/Broschueren/

GutePraxisPflanzenschutz.html

BVL Guidance Document (The Federal Office for Consumer Protection and Food Safety) (2013) 'The authorisation of plant protection products for non-professional users and for use in home gardening', http://www.bvl.bund.de/ SharedDocs/Downloads/04_Pflanzenschutzmittel/PSM Haus_und_Kleingarten_EN.pdf?_blob=publicationFile \&v $=2$

BVL Guideline (The Federal Office for Consumer Protection and Food Safety) (2006) 'Guidelines for requirements concerning personal protective equipment in plant protection', http://www.bvl.bund.de/SharedDocs/Downloads/04_Pflanzen schutzmittel/RiLi_Schutzausruestung.pdf?_blob=publicationFile $\& v=3$

Directive 2009/128/EC of the European Parliament and of the Council of 21 October 2009 establishing a framework for Community action to achieve the sustainable use of pesticides (OJ L309, 21.10.2009, p 71)

EFSA (2014) Guidance on the assessment of exposure of operators, workers, residents and bystanders in risk assessment for plant protection products. EFSA J 2(10):3874, http://www.efsa.europa.eu/de/efsajournal/pub/ 3874.htm

German Plant Protection Act (Gesetz zum Schutz der Kulturpflanzen, PflSchG) (BGBl. I Nr. 7, S. 148, 6.2.2012), http:// www.gesetze-im-internet.de/pflschg_2012/

Regulation (EC) No 1107/2009 of the European Parliament and of the Council concerning the placing of plant protection products on the market and repealing Council Directives 79/117/EEC and 91/414/EEC (OJ L309, 21.10.2009, p 1)

Regulation (EC) No 1272/2008 of the European Parliament and of the Council on classification, labelling and packaging of substances and mixtures, amending and repealing Directives 67/548/EEC and 1999/45/EC, and amending Regulation (EC) No 1907/2006, (OJ L353, 16.12.2008, p 1)

Regulation (EU) No 284/2013 of the European Parliament and of the Council setting out the data requirements for plant protection products, in accordance with Regulation (EC) No 1107/2009 of the European Parliament and of the Council concerning the placing of plant protection products on the market (OJ L93, 01.03.2013, p 85)

TRGS 512, Committee on Hazardous Substances, BAuA, 2007, latest amendment GMBl 2012, p 875 (No 45/46), “Technical Rules for Dangerous Substances 512”

TRGS 900, Committee on Hazardous Substances, BAuA, BArBl 2006(1), pp 41-55, latest amendment GMBl 2015, pp 139-140 (No 7), "Technical Rules for Dangerous Substances 900" 